
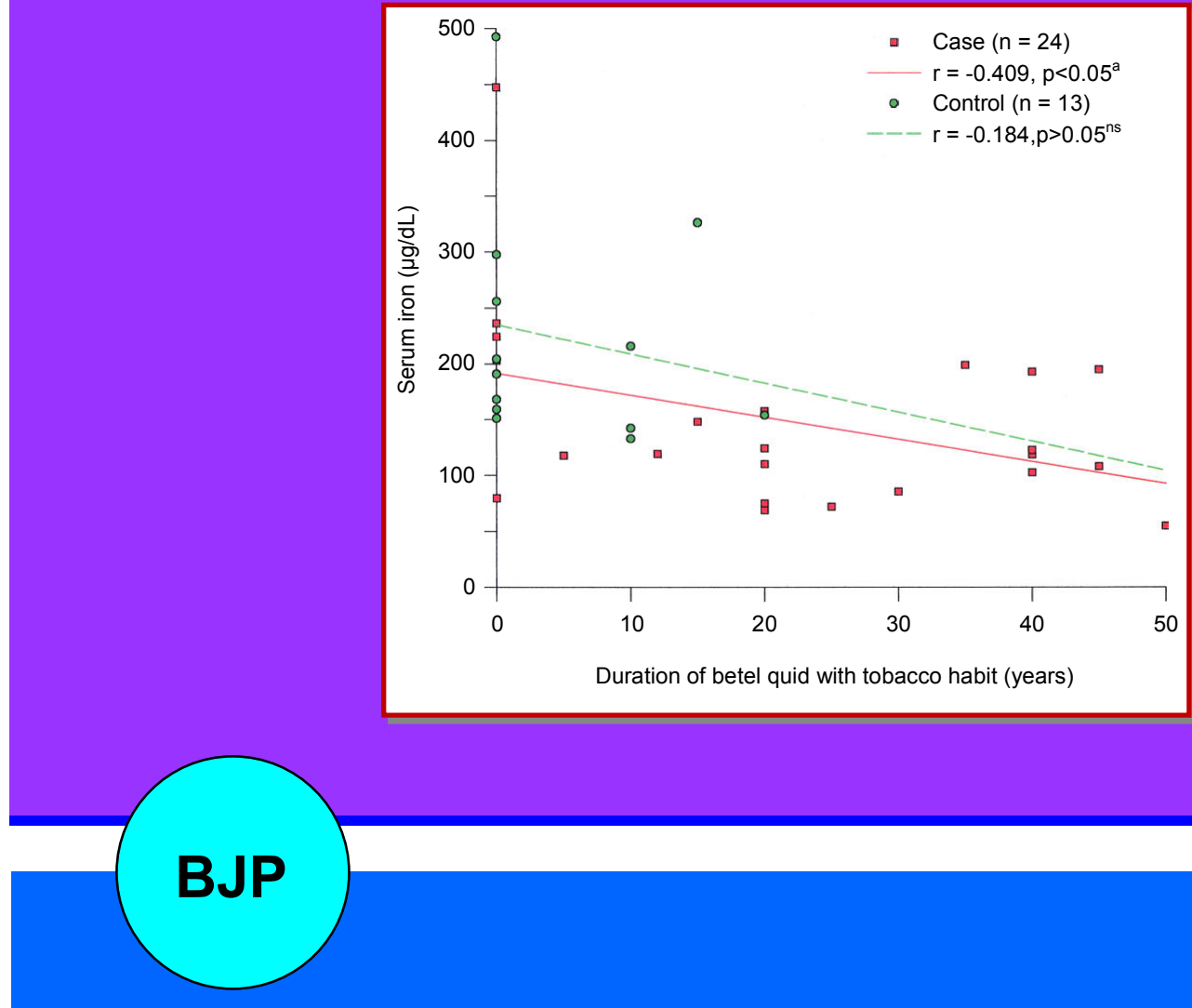

Bangladesh Journal of Pharmacology

Research Article

Serum iron concentration and total iron binding capacity in patients of oral squamous cell carcinoma 
Abstracted/indexed in Academic Search Complete, Asia Journals Online, Bangladesh Journals Online, Biological Abstracts, BIOSIS Previews, CAB Abstracts, Current Abstracts, Directory of Open Access Journals, EMBASE/Excerpta Medica, Google Scholar, HINARI (WHO), International Pharmaceutical Abstracts, Open J-gate, Science Citation Index Expanded, SCOPUS and Social Sciences Citation Index;

ISSN: $1991-0088$

\title{
Serum iron concentration and total iron binding capacity in patients of oral squamous cell carcinoma
}

\author{
Shakhawat Hossain, Motiur Rahman Molla and Mahmuda Akhter
}

Department of Oral and Maxillofacial Surgery, Faculty of Dentistry, Bangabandhu Sheikh Mujib Medical University, Shahbag, Dhaka 1000, Bangladesh.

\begin{tabular}{|c|c|}
\hline \multicolumn{2}{|l|}{ Article Info } \\
\hline & \\
\hline & \\
\hline Available Online: & 3 January 20 \\
\hline \multicolumn{2}{|c|}{ DOI: 10.3329/bjp.v2i1.500 } \\
\hline \multicolumn{2}{|c|}{$\begin{array}{l}\text { Cite this article: } \\
\text { Hossain S, Molla MR, Akhter M. Se } \\
\text { rum iron concentration and total iror } \\
\text { binding capacity in patients of ora } \\
\text { squamous cell carcinoma. Bangladesh } \\
\text { J Pharmacol. 2007; 2: 49-54. }\end{array}$} \\
\hline
\end{tabular}

\section{Abstract}

The serum iron concentration and total iron binding capacity (TIBC) status of 24 patients of oral squamous cell carcinoma (OSCC) were compared with the findings of 13 healthy subjects. OSCC was found to have association with low serum iron level. More patients were found to be with significantly lower iron content in serum $(\mathrm{p}<0.05)$. But no association between serum TIBC and increased risk of cancer was found ( $p>0.05)$. Irrespective of age, sex, smoking and betel nut chewing habit of subjects, low serum iron level significantly increase the risk of oral malignancy.

\section{Introduction}

Oral cancer is becoming a problem for all over the world and the incidence is high in the least developed or undeveloped countries like Bangladesh (WHO, 1984; Chiba et al., 1998; Watkinson, 2001; Goselin, 2006). In Bangladesh the number of new cancer cases per year is about 200,000 of which oral cancer is about $20 \%$ (Shaheed et al., 1995). Due to some geographic distribution and socioeconomic condition, the rate of oral cancer is high in our country than the developed countries. The common site of oral cancer also differs due to some habit (Hasan and Molla, 1997; Talukder and Molla, 1997).

The etiology of oral cancer is a complex, multi-factorial, ill-defined and incomplete concept. Risk factor includes betel nut, chewing tobacco, smoking, age, familial or genetic predisposition, poor oral hygiene and chronic irritation, nutritional status, alcohol, exposure to industrial products or heavy metals, viruses, ionizing radiation, oral candidiasis, etc (Goselin 2006; Binnie et al., 1983).
The etiological factors of oral squamous cell carcinoma (OSCC) are also different in different areas of the world (Shaheed et al., 1995).

Iron deficiency has long been known to have profound effects on the oral mucosa and also to have association with both oral and pharyngeal cancer (Paterson-Kelly syndrome), and with chronic candidiasis (Huggs and Wells, 1972). The findings of Joynson et al. (1972) showed an impairment of cell mediated immunity in iron deficient patients.

Deficiency as well as excess body iron, both may cause carcinogenesis. Some researchers emphasize that few habitual etiology have synergistic effect on iron to cause carcinogenesis (Bhattathiri, 2006).

The potential role of iron in cancer etiology is supported by several possible mechanisms. As transitional metals, iron can generate the reactive oxygen species including hydroxyl radical. These reactive oxygen species can attack DNA and cause DNA mutation; thus contributing to the pathological process of cancer 
(Huggs and Wells, 1972; Joynson et al., 1972; Graham et al., 1977; Toykuni, 1996; Stevens and Kalkwarf, 1990).

Iron is an essential nutrient for body. It has a central role in metabolism. It is also an essential component in DNA synthesis and in respiratory and oxidative metabolism. These functions relate to the properties of unremitting proliferation and a more anaerobic metabolism that may contribute to a selective advantage of neoplastic cells over non-neoplastic cells. Clinical correlations have been made linking cellular iron content to the development of cancer in human (Huggs and Wells, 1972; Joynson et al., 1972; Graham et al., 1977).

Severe iron deficiency leads to immune compromise, which in turn may cause cancer.

A study conducted by Rennie and Mac-Donald (1982) in United Kingdom have shown that in human iron deficiency anemia and in experimental iron deficiency in hamsters, qualitative histological changes in the oral epithelium are demonstrable.

Level of serum iron, ferritin, total iron binding capacity (TIBC) and transferrin saturation are the important diagnostic measures of iron deficiency (Hepplestone and Pippard, 1996; Dallman et al., 1980; Dallman and Reeves, 1984). So, TIBC has a relation with OSCC like serum iron. Few researchers conducted some study to get the relationship. A study conducted in India among 289 patients with epidermoid oral cancer and got relationship (Bhattathiri, 2006).

\section{Materials and Methods}

The study includes 24 (12 male, 12 female) histopathologically diagnosed OSCC patients and 13 (7 male, 6 female) healthy subjects. A detailed history of the patients including age, sex, duration of disease, greatest tumor diameter, number and size of involved lymph nodes, duration of smoking and betel nut chewing habit were taken.

\section{Collection of blood sample}

With all aseptic precaution $5 \mathrm{~mL}$ of whole blood was collected by venipuncture using disposable syringes. Blood was collected at the morning in fasting condition of the patient. Then the blood was poured into a metal free tube and taken to the laboratory of the Department of Pharmacology, Bangabandhu Sheikh Mujib Medical University, Dhaka, Bangladesh. Centrifugation of blood was done at 4,000 rpm for $10 \mathrm{~min}$ to separate the serum. Then the serum was preserved in $1.5 \mathrm{~mL}$ appendrof tube in deep freeze until measuring iron and TIBC.

All apparatus (test tubes, microtubes, pipette etc.) used in the study were made metal free.

\section{Procedure of serum iron measurement}

Iron is released from transferrin through a decrease in the $\mathrm{pH}$ of serum. In an acidic medium transferrin bound iron dissociates into free ferric ions. Hydroxylamine hydrochloride reduces the ferric ions to ferrous ions which react with ferrozine to form a strongly colored purple complex with an absorption maximum near $560 \mathrm{~nm}$. Absorbance is proportional to iron concentration.

One milliliter of reagent A (1.5 g of Hydroxylamine hydrochloride in $0.3 \mathrm{~g}$ of sodium acetate $\mathrm{pH} 4.5$ ) was taken in each test tube placed for blank, standard and unknown sample. Then $200 \mathrm{~mL}$ water in the blank, 20 $\mathrm{mL} \mathrm{FeSO}_{4}$ solution and $150 \mathrm{~mL}$ water in the standard and $200 \mathrm{~mL}$ serum in the unknown sample tube was mixed. $40 \mathrm{~mL}$ of reagent B $(24 \mathrm{mg}$ of ferrozine and 95.5 $\mathrm{g}$ of hydroxylamine hydrochloride) was mixed in 6.2 $\mathrm{mL}$ water was then placed in each tube, mixed well and wait for 10-15 min. A turnery purple colored complex was formed. Then absorbance was measured in a spectrophotometer at $560 \mathrm{~nm}$. The absorbance of blank was subtracted form the absorbance of other tubes. Then the result was calculated to get the serum iron in $\mathrm{mg} / \mathrm{dL}$.

\section{Procedure of serum TIBC measurement}

The serum unsaturated iron binding capacity and TIBC are determined by addition of sufficient $\mathrm{Fe}^{3+}$ to saturate iron binding sites on transferrin. The access $\mathrm{Fe}^{3+}$ is removed with adsorbant like light magnesium carbonate $\left(\mathrm{MgCO}_{3}\right)$ powder and the assay for iron content was then repeated. From this second measurement the TIBC was obtained.

Iron standard solution was prepared by $7.3 \mathrm{mg} \mathrm{FeCl}_{3}$ taken in $500 \mathrm{~mL}$ water and then $0.3 \mathrm{~mL}$ of hydrochloric acid was added to it. This was saturating iron solution for TIBC measurement. $0.5 \mathrm{~mL}$ of serum was taken in a test tube. $0.5 \mathrm{~mL}$ of saturating iron solution was added. Mixed well and wait for $15 \mathrm{~min}$. Then $100 \mathrm{mg}( \pm 15 \mathrm{mg})$ light magnesium carbonate $\left(\mathrm{MgCO}_{3}\right)$ was added and shake vigorously. Wait for 30-60 min. Then centrifuge it at 4,000 rpm for $10 \mathrm{~min}$. Supernatant was removed and centrifuged. $0.5 \mathrm{~mL}$ of supernatant was taken. Method of serum iron measurement was repeated using this supernatant solution instead of serum and then TIBC was calculated.

\section{Results}

The mean $( \pm$ SD) age of patients was $54.1 \pm 14.4$ years. Among them 16 patients $(66.7 \%)$ were above 50 years (Table I). But in case of healthy subjects mean age was $31.6 \pm 8.5$ years. Among the patients $8(33.3 \%)$ were smoker, $18(75.0 \%)$ were betel quid with tobacco chewer and $7(29.2 \%)$ had both smoking and betel chewing habit. But in case of healthy subjects only $4(30.8 \%)$ 


\section{Table I}

\section{Distribution of age and sex of the subjects}

\begin{tabular}{|c|c|c|}
\hline Parameters & Number of case & Number of control \\
\hline \multicolumn{3}{|l|}{ Age } \\
\hline Up to 25 & 1 & 3 \\
\hline $26-50$ & 7 & 10 \\
\hline 51 and above & 16 & 0 \\
\hline \multicolumn{3}{|l|}{ Sex } \\
\hline Male & 12 & 7 \\
\hline Female & 12 & 6 \\
\hline
\end{tabular}

Table II

\section{Level of serum iron and TIBC in males and females}

\begin{tabular}{|cccc|}
\hline Parameters & Case & Control & p value \\
\hline Serum iron $(\mu g / d L)$ & & & \\
Male & 160.8 & 198.5 & $>0.10$ \\
& $(105.7)$ & $(57.6)$ & \\
Female & 136.3 & 250.0 & $<0.05$ \\
& $(55.3)$ & $(137.6)$ & \\
p value & $>0.1$ & $>0.1$ & \\
& & & \\
TIBC $(\mu g / d L)$ & & & \\
Male & 189.2 & 236.2 & $<0.05$ \\
& $(46.1)$ & $(34.1)$ & \\
Female & 205.1 & 223.7 & $>0.50$ \\
& $(81.3)$ & $(56.2)$ & \\
p value & $>0.5$ & $>0.5$ & \\
\hline
\end{tabular}

were smoker, 5 (38.5\%) were betel quid with tobacco chewer and only one had both smoking and betel chewing habit.

The duration of smoking habit in patient and healthy controls were $8.7 \pm 14.5$ years and $2.7 \pm 7.0$ years respectively. The mean duration of betel quid with tobacco chewing habit was $21.8 \pm 17.1$ years in patients and $5.0 \pm 7.1$ years was in healthy controls. Here the difference was statistically significant $(\mathrm{p}<0.01)$.

The mean serum iron level in case of male study group was $160.8 \pm 105.6 \mathrm{mg} / \mathrm{dL}$ and in male control $198.5 \pm$ $57.6 \mathrm{mg} / \mathrm{dL}$ where the difference was not significant (Table II). But mean serum iron in case of female study group was $136.3 \pm 55.3 \mathrm{mg} / \mathrm{dL}$ and female control 250.0 $\pm 137.6 \mathrm{mg} / \mathrm{dL}$. Mean serum iron was lower in case of female patient than the healthy female control and the result is statistically significant $(\mathrm{p}<0.05)$.

Considering the tumor size the highest number of cases (10) was in $\mathrm{T}_{2}$ (2-4 cm; Table III). The lowest level of iron was in $\mathrm{T}_{4}$ size $(87.0 \pm 45.3 \mathrm{mg} / \mathrm{dL})$ and the highest was in $\mathrm{T}_{1}$ size $(233.1 \pm 134.0 \mathrm{mg} / \mathrm{dL})$. Serum iron level decreased with the increasing of size of the lesion. The TIBC level was lowest in $\mathrm{T}_{3}(164.4 \pm 47.7 \mathrm{mg} / \mathrm{dL})$ and highest in $\mathrm{T}_{1}(250.0 \pm 88.0 \mathrm{mg} / \mathrm{dL})$. Unlike serum iron level, TIBC level was not correlated with the size of lesion. Regarding the histopathological grading the highest number of cases $(41.7 \%)$ was found as grade II. Serum iron level decreased with the increase in number of grade. TIBC level was not correlated with histopathological grading.

With the increase of duration of betel quid with tobacco chewing habit serum iron level of OSCC patient decreased $(r=-0.409)$ which was significant (Figure 1). In case of healthy control group serum iron also decreased $(r=-0.184)$ but the result was not significant $(p>0.50)$. With the increase of duration of betel quid with tobacco chewing habit TIBC level decreased $(r=-$ $0.101)$ in OSCC patient insignificantly $(p>0.50)$.

Iron level also decreased markedly $(r=-0.579)$ with the increase of duration of cancer (Figure 2). TIBC also decreased but not markedly.

\section{Table III}

\begin{tabular}{|lccc|}
\hline & \multicolumn{2}{c}{ After RAA treatment } & \\
\hline Parameter & $\mathrm{n}$ & $\begin{array}{c}\text { Serum iron }(\mu \mathrm{g} / \mathrm{dL}) \\
(\text { Mean } \pm \mathrm{SD})\end{array}$ & $\begin{array}{c}\text { Serum TIBC }(\mu \mathrm{g} / \mathrm{dL}) \\
(\mathrm{Mean} \pm \mathrm{SD})\end{array}$ \\
\hline Size of lesion & & & $174.0 \pm 2.8$ \\
$<2 \mathrm{~cm}\left(\mathrm{~T}_{1}\right)$ & 2 & $233.1 \pm 134.0$ & $210.8 \pm 44.8$ \\
$2-4 \mathrm{~cm}\left(\mathrm{~T}_{2}\right)$ & 10 & $134.9 \pm 53.6$ & $146.4 \pm 47.7$ \\
$>4 \mathrm{~cm}\left(\mathrm{~T}_{3}\right)$ & 7 & $125.1 \pm 43.5$ & $250.0 \pm 88.1$ \\
Any size involving adjacent structure $\left(\mathrm{T}_{4}\right)$ & 5 & $87.0 \pm 45.3$ & $223.7 \pm 77.1$ \\
Histopathological grading & & & $178.0 \pm 58.2$ \\
$\quad$ Grade I & 8 & $223.3 \pm 102.5$ & $193.5 \pm 56.9$ \\
Grade II & 10 & $130.3 \pm 28.6$ & $79.2 \pm 21.8$ \\
$\quad$ Grade III & 6 & & \\
\hline
\end{tabular}




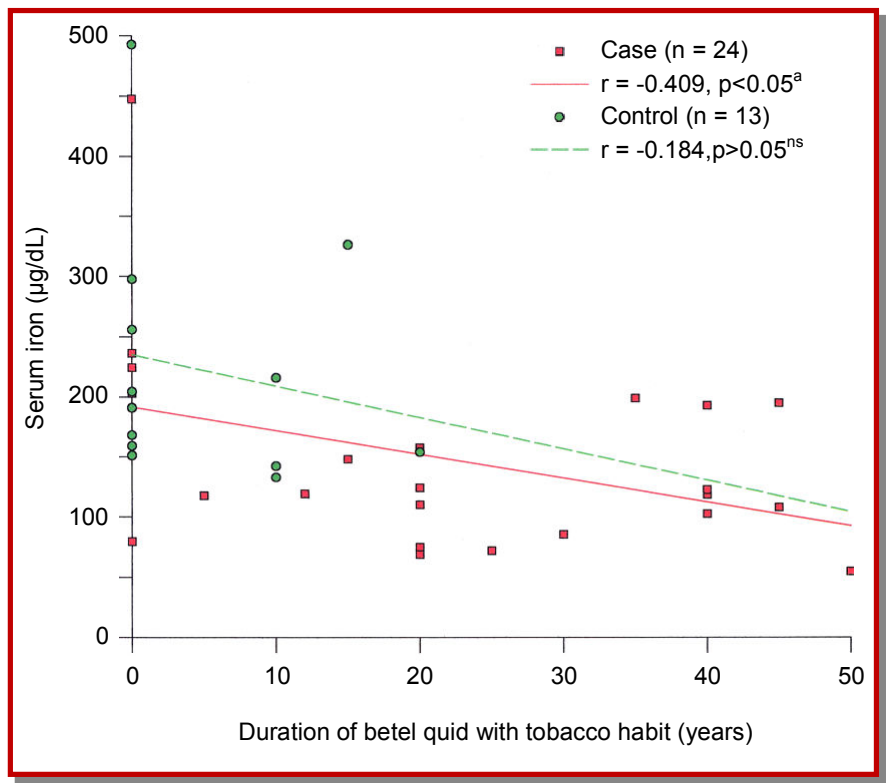

Figure 1: Relationship between serum iron concentration and duration of intake of betel quid with tobacco

\section{Discussion}

Researches across the globe endeavored to elucidate possible relationship of trace elements with the risk of cancer in humans. Several of their ventures uncovered the peril related with several familiar trace elements, particularly with zinc, copper, iron, TIBC and ferritin as well. Iron deficiency has long been documented to have profound effects on the oral mucosa and some even tries times link it with both oral and pharyngeal cancer (Graham et al., 1977). Attempts of clinical correlation were also made by several clinical epidemiologists in this regard to establish a causal mechanism of malignancy inflicted by deficiency or excess of trace elements (Joynson et al., 1972).

Present study was conducted among 24 OSCC patients to find out the association of serum iron and TIBC with OSCC. Thirteen control subjects were also taken to facilitate comparison between cancer and non cancer subjects.

Biochemistry of iron, suggests that this metal may play an important role in carcinogenesis (Toyokuni, 1996). Meta analysis of studies conducted to uncover the relation of these trace elements with cancer risk failed to reach conclusive agreement. Although several of them confirmed the relationship (Stevens et al., 1988; Knekt et al., 1994; Merk et al., 1990). Further epidemiological evidence was provided by Ahlbom (1936). Iron is a component of the enzyme system which catalyze the electron-transfer and respiration reaction which are essential for cell viability (Neilands, 1972).

In present investigation serum iron level were com- pared between the two groups. Serum iron content were found to be significantly low among the OSCC patients $(p<0.05)$ than the healthy control in the study. Serum iron level individually in male was low but insignificant $(p>0.05)$ but incase of female it is significantly low $(\mathrm{p}<0.05)$. Results of several studies have been consistent with present study result. TIBC also found lower in OSCC patient then control but it was insignificant $(p>0.10)$. When serum TIBC was analyzed separately in men and women, TIBC level in case of male OSCC patient was significantly lower than male healthy control. It is also lower in female patient, but insignificant. Stevens (1994) described low serum iron is clearly detrimental. A study conducted by Rennie and MacDonald (1982) in United Kingdom have shown that in human iron deficiency anemia and in experimental iron deficiency in hamsters, qualitative histological changes in the oral epithelium are demonstrable. Study conducted by Bhattathiri (2006) suggested like present study that iron promotes cancer growth. They further emphasize iron as a factor for treatment and prevention of neoplastic diseases. Bhattathri's study was conducted in India, almost similar socio demographic distribution like Bangladesh. He found nearly one-third of the patients were hypoferrimic and this was more in women. Women had lesser serum iron, TIBC and serum ferritin than men. Although in his study smoking has been identified as a strong confounder.

In the current study serum iron level decreased significantly $(\mathrm{p}<0.05)$. With the increasing of size, duration of cancer, and duration of betel quid with tobacco chewing. TIBC also decrease but insignificantly. 


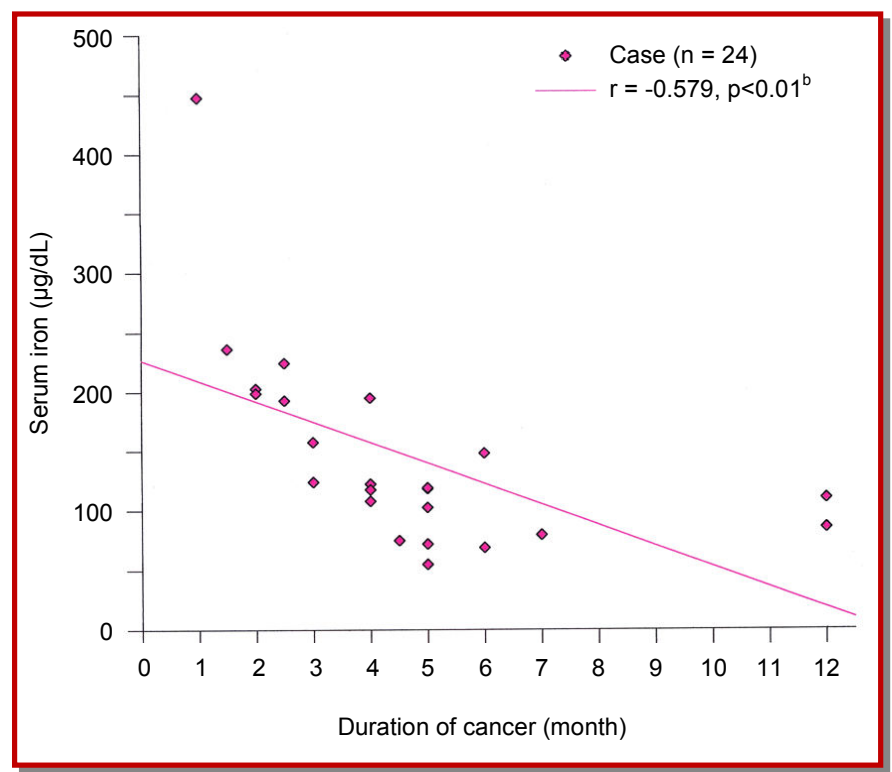

Figure 2: Relationship between serum iron concentration and duration of cancer

Baseline parameter in the study were analyzed and in the distribution of age, significant deference exists in between 26-50 years of age group. Duration of betel quid chewing habit was also significant. Majority of the malignancy were diagnosed with $\mathrm{T}_{2}$ tumor size and histopathological grade II. In line with biochemical evidence OSCC is found to be association with low serum iron level. In the current study serum total iron binding capacity was also lower in oral cancer patients but insignificant.

\section{Acknowledgement}

We are grateful to Prof. Mir Misbahuddin of Bangabandhu Sheikh Mujib Medical University for allowing us to use his laboratory.

\section{References}

Ahlbom HE. Simple achlorhydric anaemia, Plummer-Vinson syndrome and carcinoma of the mouth, pharynx and oesophagus in women. BMJ. 1936; 2: 331-33.

Bhattathiri VN. Paradoxes in iron indices in oral cancer patients vis-a-vis tobacco-alcohol habits. Health Administrator. 2006; 17: 76-82.

Binnie WH, Rankin KV, Mackenzie IC. Etiology of oral squamous cell carcinoma. J Oral Pathol. 1983, 12: 11-29.

Chiba I, Muthumala M, Yamazaki Y. Characteristics of P53 gene of oral squamous cell carcinomas associated with betel quid chewing in Sri Lanka. Int J Cancer. 1998; 77: 839-42.

Dallman PR, Reeves JD. Laboratory diagnosis of iron deficiency. In: Iron nutrition in infancy and childhood. Stekel
A (ed), New York, Raven Press, 1984, pp 11-24.

Dallman PR, Siemes MA, Stekel A. Iron deficiency in infancy and childhood. Am J Clin Nutr. 1980; 33: 89-118.

Gosselin BJ. Malignant tumors of the mobile tongue. http// www.emedicine.com. 2006; 8: 1-18.

Graham S, Dayal H, Rohrer T, Swanson M, Sultz H, Shedd D, Fischman S. Dentition, diet, tobacco and alcohol in the epidemiology of oral cancer. J Natl Cancer Inst. 1977; 59: 1611-16.

Hasan MN, Molla MR. Primary sites, clinical staging and histological grading of 102 oral squamous cell carcinoma. Bangladesh Dental J. 1997; 12: 17-21.

Hepplestone AD, Pippard MJ. Microcytic and macro-cytic anemia. Med Group J. 1996, 23: 4-10.

Huggs JM, Wells RS. Chronic mucocutaneous candi-diasis associated abnormalities of iron metabo-lism. Br J Dermatol. 1972; 86: 88-102.

Joynson DH, Walker DM, Jacobs A, Dolby AE. Defect of cellmediated immunity in patients with iron-deficiency anaemia. Lancet 1972; 2: 1058-59.

Knekt P, Reunanen A, Takkunen H, Aromaa A, Heliovaara M, Hakulinen T. Body iron stores and risk of cancer. Int J Cancer. 1994; 56: 379-82.

Merk K, Mattsson B, Mattsson A, Hold G, Gullbring B, Bjorkholm $\mathrm{M}$. The incidence of cancer among blood donors. Int J Epidemiol. 1990; 19: 505-9.

Neilands JB. Evolution of biological iron binding center. Structure Bonding. 1972; 11: 145-70.

Rennie JS, MacDonald DG. Quantitative histological analysis of the epithelium of the ventral surface of the hamster tongue in iron deficiency. Arch Oral Biol. 1982;

Shaheed I, Hossain A, Molla MR. Histological and causative 
factor of oral cancer in Bangladesh. Oral Oncology, Applied. Proceedings of the 4th International Congress on Oral Cancer. Ogaki City, Japan, 1995, pp 27-30.

Stevens RG, Graubard BI, Micozzi MS, Nerishi K, Blumberg BS. Moderate elevation of body iron level and increased risk of cancer occurrence and death. Int J Cancer 1994; 56: 364-69.

Stevens RG, Joncs DY, Micozzi MS, Taylor PR. Body iron and the risk of cancer. N Engl J Med. 1988; 319: 1047-52.

Stevens RG, Kalkwarf DR. Iron, radiation and cancer. Environ Health Perspect. 1990; 87: 291-300.
Talukder MA, Haq R, Molla MR. A retrospective study of oral cancer and its cervical lymph nodes metastasis in Bangladesh. Bangladesh Dental J. 1997; 13: 21-26.

Toyokuni S. Iron-induced carcinogenesis: the role of Redox regulution. Free Radi Biol Med. 1996; 20: 553-66.

Watkinson JC, Gaze MN, Wilson JA. Stell and Maran's Head and neck surgery. 4th ed, 2001, pp 1-3.

World Health Organization. Control of oral cancer in developing Countries; From the report of WHO meeting, Colombo, Bull WHO 62, Sri Lanka, 1984, pp 817-30. 